Gwen Lawrie, THE UNIVERSITY OF QUEENSLAND, g.lawrie@uq.edu.au

Elizabeth Marquis, MCMASTER UNIVERSITY, beth.marquis@mcmaster.ca

Eddie Fuller, WEST VIRGINIA UNIVERSITY, ejfuller@mail.wvu.edu

Tara Newman, UNIVERSITY OF SOUTHERN QUEENSLAND, NewmanTara07@gmail.com

Mei Qiu, THE UNIVERSITY OF QUEENSLAND, mei.qiu@uq.net.au

Milton Nomikoudis, RMIT UNIVERSITY, milton.n@rmit.edu.au

Frits Roelofs, HAN UNIVERSITY OF APPLIED SCIENCES, Frits.Roelofs@han.nl

Lianne van Dam, HAN UNIVERSITY OF APPLIED SCIENCES, vandam.lianne@gmail.com

\title{
Moving Towards Inclusive Learning and Teaching: A Synthesis of Recent Literature
}

\section{ABSTRACT}

The need for inclusive and equitable approaches to teaching and learning is a persistent theme in recent literature. In spite of relatively widespread agreement about this objective, inclusion remains elusive, and opinions about how best to achieve it proliferate. To provide a landscape view of the field and offer recommendations for research and practice, this article provides a focussed review of literature connected to inclusive teaching and learning published since 2010. Drawing from a framework advanced by Hockings (2010), we synthesize key findings from recent scholarship and argue for the value of a whole-of-institution approach that considers the activities and interactions of educational actors operating at different institutional levels. We also extend this argument to consider the need for greater attention to factors that move beyond the individual institution and to advocate for further international research in particular.

\section{KEYWORDS}

inclusive teaching and learning, inclusive curriculum design, inclusive curriculum delivery, inclusive assessment, institutional commitment to inclusion

\section{INTRODUCTION}

Questions of inclusion and equity in teaching and learning have been explored by multiple higher education stakeholders in recent years. Scholars and policymakers alike have discussed the importance of widening participation in tertiary education (e.g., Bradley \& Miller, 2010) and of developing campus cultures and pedagogical approaches that value, respect, and work for a wide variety of learners (e.g., Grace \& Gravestock, 2009; Ouellett, 2005). Much of this scholarship has focused on the relative accessibility of teaching and learning for students with disabilities in particular (e.g., Fuller, Bradley, \& Healey, 2004; Riddell, Weedon, Fuller, Healey, Hurst, Kelly, \& Piggott, 2007), often considering inclusive pedagogical strategies such as universal design for learning (Burgstahler \& Cory, 2009). Considerable attention has also been afforded to the ways in which teaching and learning intersect with ethnicity, socio-economic status, religion, and other axes of identity (e.g., Cole \& Ahmadi, 2010; Devlin, Kift, Nelson, Smith, \& McKay, 2012; Ladson-Billings, 2014; MacKinnon \& Manathunga, 
2003). In line with this growing body of work, Ainscow, Booth, and Dyson (2006) suggest that inclusion has become a global agenda for educational institutions, arguing that all such institutions "should concern themselves with increasing the participation and broad educational achievements of all groups of learners who have historically been marginalized" (p. 295).

This imperative has been taken up in a range of ways, with conceptualizations and definitions of inclusion proliferating across the literature and in practice. In this respect, scholarship focusing on inclusive learning and teaching resembles the Scholarship of Teaching and Learning (SoTL) more broadly: different people use the relevant terms in different ways and for varying purposes. Indeed, just as Trigwell (2013) notes that the SoTL community has begun to recognize the need to "move beyond the search for a common definition or a unifying conceptualisation” (p.95), so too do May and Bridger (2010) cite individuals who argue that one cannot conclusively define terms related to inclusion "because they have different meanings depending on the different point [s] of view of people historically and [in] different contexts" (p. 31). In this article, we seek to recognize this diversity of understanding rather than advocate for a singular conception of inclusion. Nevertheless, like Trigwell (2013) in his discussion of SoTL, we acknowledge that some attention to terms is necessary to clarify our focus. To that end, we frame the following discussion around a definition provided by Hockings (2010), who argues that "inclusive learning and teaching in higher education refers to the ways in which pedagogy, curricula and assessment are designed to engage students in learning that is meaningful, relevant, and accessible to all" (p. 1).

This broad definition has much to recommend it. To begin with, while research focusing on particular student groups has generated a number of valuable insights, authors have recently argued that a more adequate understanding of inclusion requires attention to the complex, dynamic, and intersecting identities that all learners and teachers bring to the pedagogical experience (Gibson, 2015; Longstreet, 2011). Thomas and May (2010), for example, suggest four broad dimensions of diversity across which students might differ (educational, dispositional, circumstantial, and cultural), thereby highlighting that all students bring to bear complex constellations of attributes and experiences that vary from those of their peers and from proposed 'normative' standards. Like Hockings (2010), they thus argue for an approach to inclusion that doesn't target particular groups, but instead "strives towards proactively making higher education accessible, relevant and engaging to all students” (p. 5).

At the same time, while focusing on teaching and learning specifically, Hockings' (2010) definition makes room for considering how broader institutional factors relate to and impinge upon the educational encounter. This is again consistent with trends in the literature. Whereas academic faculty are often positioned as key players in determining the relative inclusivity of learning and teaching (e.g., Moriña Díez, López Gavira, \& Molina, 2015; Thomas \& Heath, 2014), and the teaching and learning context is seen as a primary site at which inclusion and exclusion are enacted (e.g., Brookfield, 2007), some scholars have begun to articulate the need for integrated approaches to inclusion, which consider the roles of all members of campus communities in working towards this goal. Hockings herself (2010), for instance, draws from a review of existing literature to offer recommendations for senior management, instructors, students, academic developers, and student services staff, while Riddell et al. (2007) consider the experiences of administrators and staff in working towards accessibility for disabled students. Again, the movement in such work is toward increased nuance and complexity, which acknowledges the multiple players and intersecting factors that contribute to the relative inclusivity of any educational environment.

Of course, such a broad approach to educational inclusion is challenging, and the issue thus 
remains unresolved in educational research and largely unrealized in practice. The task may be especially daunting for large organizations with significant numbers of learners with widely varying identities and experiences. Indeed, absolute inclusivity can only exist in the ideal. Nevertheless, the significance of the goal suggests the importance of striving continually to reach it. This is the motivation underpinning our work in this article.

In particular, this piece seeks to build on Hockings' (2010) review of the literature on inclusive learning and teaching in order to understand better the state of the field and offer recommendations for further research and practice. In her review, which represents a touchstone for the current article, Hockings outlines four broad areas of focus which align with the definition provided above: inclusive curriculum design, inclusive curriculum delivery, inclusive assessment, and institutional commitment to and management of inclusive learning and teaching. The boundaries between these categories are somewhat fuzzy. Inclusive curriculum design, for instance, may take into account considerations of delivery (i.e., particular pedagogical practices deployed in teaching contexts) or assessment. Nevertheless, these four areas provide a useful heuristic for considering the range of ways questions of inclusion might play out in relation to teaching and learning. By summarizing existing scholarship of relevance to each of these areas, Hockings offers a compelling sense of the state of the field in 2010. With this in mind, we sought to build on and test her findings through a review of research published in the intervening years. By analysing a wide range of sources and bringing our international experiences to bear, we seek to answer the following questions:

1. To what extent and in what ways has scholarship about inclusive learning and teaching developed since Hockings' review?

2. What gaps in the literature remain, and what do these suggest about directions for future research?

Since 2010, scholars have attempted to address inclusion at a number of levels — from programmatic initiatives that span entire organizations to specific activities targeting subgroups of students for differentiated instruction. Across this broad landscape, numerous researchers continue to add outcomes from their work, creating a need for ongoing synthesis that provides actionable guidance for future efforts. We aim to provide such a synthesis in this piece.

Moreover, by considering work drawn from a range of higher education literatures and focusing on institutional contexts that include, but are not limited to, the classroom, we also seek to contribute to broadening discussions of equity and inclusion within the Scholarship of Teaching and Learning specifically. While many SoTL scholars have explored questions about accessibility and inclusion in teaching and learning, much of this work tends to focus on particular pedagogical strategies deployed at the classroom level (e.g., Dierker, Alexander, Cooper, Selya, Rose, \& Dasgupta, 2016; Smith, 2012) or on educational development initiatives that support such classroom-level work (e.g., Considine, Mihalick, Mogi-Hein, Penick-Parks, \& Van Auken, 2014; Glowacki-Dudka, Murray, \& Concepción, 2012). Such scholarship is undoubtedly significant and continues to make important contributions to the goals articulated in this paper. Nevertheless, in line with the 'whole-of-institution' approach described above and increasingly advocated, we believe that SoTL scholars and readers might benefit from further consideration of the ways in which this 'hands-on' work could be integrated with activities located at other institutional levels. 


\section{METHODOLOGY}

Prior to locating Hockings' review, we conducted a broad-ranging, preliminary literature search to help us identify the scope of the existing research in this area. A challenge faced during this process was the fluid use of terminology applied around the notions of inclusion and equity, as described above. To focus our search, we sought articles and scholarly reports (from across the SoTL and broader education literatures) written in the languages spoken by members of our group (English, Dutch, German, and Mandarin) and related to the terms inclusion, inclusive, or inclusivity (e.g., 'inclusive education,' 'inclusive learning and teaching,' 'inclusive practice,' 'inclusive pedagogies,' 'inclusive curriculum,' 'inclusive assessment'). As such, while this search yielded work that takes up the notion of inclusion in varying ways, it did not necessarily access scholarship drawing on related but differing terms (e.g., diversity in education, culturally-responsive teaching, accessible education.) We initially limited our search to work focusing on higher education published since 2005, though agreed that we would consider works on school education and/or written before 2005 if they appeared to be seminal. Beyond this search of the literature, we also drew on work familiar to members of our international team of authors. Based on these initial processes, sixty works were identified as relevant to our focus and reviewed, providing us with a preliminary understanding of broad trends in the literature.

The subsequent discovery of Hockings' (2010) report encouraged us to sharpen our research questions and approach by positioning her review as a touchstone for our own. We thus returned to our initial pool of sources to highlight pieces that were published in 2010 or later. Key sources published prior to 2010, which were located in our initial search but not included in Hockings' review, were also included to further increase the comprehensiveness of the data set. This resulted in a total of fifty-three scholarly sources on which this review is principally based. While this corpus of texts certainly does not include all work conducted in this area, it nonetheless encompasses a broad variety of examples that together provide insight into the current state of the literature. Thus, like Hockings (2010), we position our review as "illuminatory, rather than exhaustive of the field" (p. 21).

The articles located were subsequently considered in relation to Hockings' synthesis. We organised our findings according to her four lenses (inclusive curriculum design, inclusive curriculum delivery, inclusive assessment, and institutional commitment to inclusive learning and teaching) and created tables highlighting occasions on which a selection of the articles we examined corroborated her findings and/or offered new ideas connected to these broad areas. Finally, we worked to identify existing gaps and to develop recommendations and a framework based on the materials reviewed. Additional spot searches of the literature were conducted to check our developing conclusions and add to our pool of sources during the writing of this manuscript.

A central part of our focus is to tease out and make clearer the connections amongst Hockings' four areas of inclusion and the different stakeholder groups involved in each. To this end, we have developed our own guiding model (Figure 1) to represent and acknowledge the idealised integration of relationships and practices between stakeholders, while recognising the role of individuals' dispositions and experiences as well as external influences.

In this model, the stakeholders surround a nexus in practice which represents a 'whole-ofinstitution' approach. Similarly, we focus in this review on ways in which research suggests course design, delivery, and assessment might connect with institutional features and attempt to provide guidance for enhancing the intra- and inter-level relationships within institutions attempting to implement inclusive teaching and learning practices. 
Figure 1. Schematic representation of the shared understanding and relationships required between stakeholders as part of a whole institution approach to inclusive teaching and learning

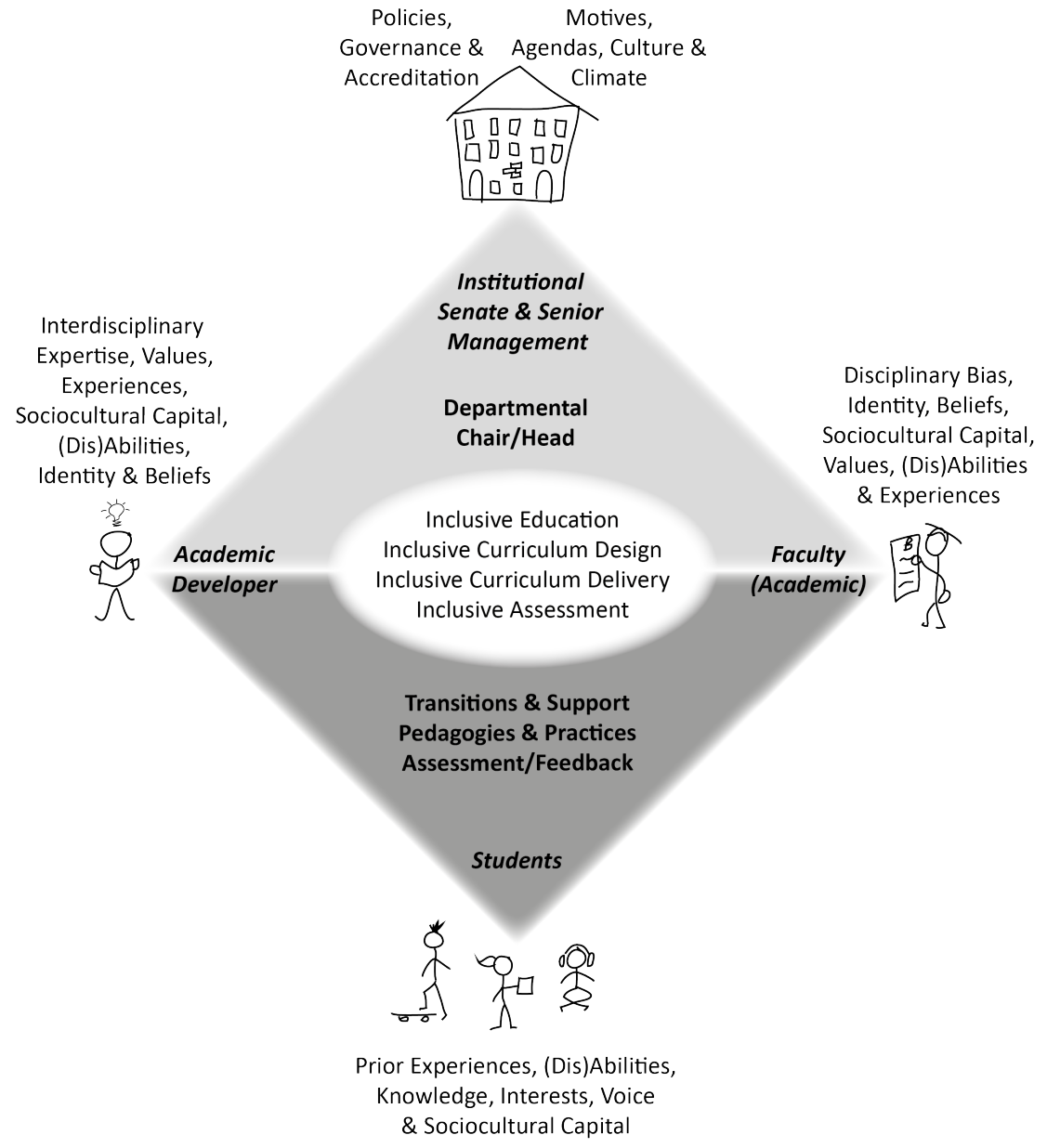

\section{RESULTS AND DISCUSSION}

A persistent theme evident throughout our review was the multiplicity of ways in which the term 'inclusive' is applied. Our findings draw from studies in which 'inclusive' is used to refer to one or more of the following ideas, amongst others:

- pedagogies should meet the diversity of learners' needs, and should not create barriers for particular students or student groups;

- pedagogies should enable accessibility and be crafted through consultation amongst a variety of institutional stakeholders;

- assessment should be multimodal and flexible while maintaining academic standards;

- institutions should adopt a more holistic, comprehensive approach to supporting teaching and learning for diverse groups of learners.

This range of ideas is not surprising, given the diverse conceptions of inclusion noted in the introduction above. While we acknowledge that different studies have different foci and emphases, we aim to bring together these conceptions here insofar as they might complement one another in meeting Hockings' definition of inclusive learning and teaching in higher education. Indeed, to some extent, each of these 
conceptions points toward ways in which "pedagogy, curricula and assessment are designed to engage students in learning that is meaningful, relevant, and accessible to all” (Hockings, 2010, p. 1).

\section{Inclusive curriculum design}

In line with Hockings' findings, evidence has continued to emerge that universal design for learning (UDL) has considerable potential for developing inclusive curricula (Kumar \& Wideman, 2014; Smith, 2012). It is important that the curriculum is designed proactively for heterogeneity and that we move away from deficit models that refer to special arrangements or remediation. Similarly, studies have continued to emphasize that retroactive accommodation is more likely to create or simply mitigate barriers than remove them (Hughes, Corcoran, \& Slee, 2015; Moriña Díez, López Gavira, \& Molina, 2015). In contrast, 'universal' approaches to curriculum design necessarily engage students as partners by offering flexibility and opportunities to customize their learning (Shuman, 2007; Kumar \& Wideman, 2014). Moreover, they benefit faculty and staff along with students (Kumar \& Wideman, 2014), require faculty professional development (Marquis, Jung, Fudge Schormans, Lukmanji, Wilton, \& Baptiste, 2016a), and are shaped by teaching experience, training, and disciplinary background (Dallas, Upton, \& Sprong, 2014). These last points, not emphasized by Hockings, provide further support for the 'whole-of-institution' approach we advocate.

A theme originally identified by Hockings (2010) and sustained in subsequent research is the need to question the exclusive assumptions embedded in disciplinary curricula (Marquis, Jung, FudgeSchormans, Vajoczki, Wilton, Baptiste, \& Joshi, 2012; Marquis, Fudge Schormans, Jung, Vietinghoff, Wilton, \& Baptiste, 2016b). However, some recent work also suggests the potential of disciplinary ways of thinking to foster inclusion, pointing out that the content and epistemologies of some disciplines are perceived to align with the flexibility and calls for equity and justice characteristic of inclusion. Drawing on this idea, Marquis et al. (2016b) underline the importance of considering the ways in which questions of accessibility in teaching and learning might overlap with ways of thinking and practicing in particular departmental contexts, again suggesting the potential for disciplines and larger institutional structures to contribute to or work against inclusion in significant ways.

Taken together, such findings highlight the need for approaches to inclusive curriculum design that extend beyond the efforts of individual instructors. While not entirely novel, this dimension has not always been sufficiently emphasized in inclusion efforts, and thus represents an important finding from the current review.

\section{Inclusive curriculum delivery}

Activity around pedagogies for diversity, commonality, and inclusivity has continued to gain momentum in the past five years. Initiatives towards enhancing practices include the implementation of professional development programs (Hockings, Brett, \& Terentjevs, 2012) and the development of instruments that aim to measure the degree of inclusion evident in teachers' practice and reflection (Cunningham, 2013). Aligning with UDL principles, common recommendations emphasize the value of presenting information in multiple ways and offering multiple means of engagement (Kumar \& Wideman, 2014; Madriaga, Hanson, Heaton, Kay, Newitt, \& Walker, 2010; Moriña, Cortés-Vega, \& Molina, 2015). Likewise, Avermaet and Sierens (2012) claim that teachers should combine informal and formal learning to improve the knowledge and skills of students from different social and ethnic backgrounds.

In a seminal article, Tervalon and Murray-Garcia (1998) argue that learning is better achieved when it involves an equal relationship and shared communication between individuals, regardless of 
imbalances in power and privilege. Lee, Williams, Shaw, and Jie (2014) offer some support for this contention, suggesting that opportunities to learn about others through interaction and to practice respectful and reflective communication build enhanced intercultural learning. However, our review of recent literature suggests there are still challenges in establishing that shared understanding. For example, teachers often confuse suitable education with inclusive education (Van Gastel, Erkaslan, \& De Jongste, 2014), and educator attitudes may impinge on accessibility (Ashworth, Bloxham, \& Pearce, 2010) or militate against inclusion (Moriña Díez, López Gavira, \& Molina, 2015; Hughes, Corcoran, \& Slee, 2015; Marquis et al., 2016b). Indeed, Groeneweg (2015) finds that the quality of education is deteriorating, particularly through the greater attention that is focussed on weaker students. These findings resonate strongly with those reported by Hockings (2010) and highlight the ongoing challenges in capturing and communicating exemplars of excellent practice.

In examining specific pedagogical strategies that may enable or inhibit inclusion, group work is often highlighted as a practice of particular interest. Madriaga et al. (2010) found that students both with and without disabilities experienced parallel barriers to group work, while Kimmel and Volet (2012) reported that bringing people together in intercultural groups as a strategy did not in itself increase tolerance and collaboration. These results, echoing points made by Hockings (2010), should not be surprising; trust, bonding, and an inclusive learning dynamic cannot be created and nurtured simply by placing people together. Developing inclusive group work is a multidimensional process, and participating individuals require an understanding and acceptance of factors ranging from why they are in the group to how the group will function and how they as individuals can be respected and included in the learning process.

Moreover, consideration must also be given to the ways in which group work might create a context in which pre-existing prejudices and attitudinal barriers can present particularly strongly (Marquis et al., 2012). With this in mind, these findings might also be taken to indicate the importance of moving beyond surface considerations of inclusive and equitable pedagogical techniques used by individual educators to refocus attention on the larger social, cultural, and institutional structures within which pedagogical choices are deployed (McArthur, 2010). Again, then, this resonates with the idea of exploring pedagogical strategies as only one piece of a complex puzzle connected to equity and inclusion in teaching and learning.

\section{Inclusive assessment}

Hockings (2010) raised important challenges in regard to inclusive assessment, asking what represents 'fair assessment' and whether it can truly be 'fair for all.' Since the time of her writing, further literature has corroborated the notion that current assessment methods introduce barriers to a wide range of students. Madriaga et al. (2010) suggest that disabled and non-disabled students experience similar assessment barriers, for instance, while Butcher, Sedgwick, Lazard, and Hey (2010) illustrate that conventional higher education assessment methods disadvantage academically weak students. Likewise, there is still a great demand for holistic systems to be established for the improvement of assessment practices and the support of students completing assessments. Along these lines, recent scholarship reiterates the value of introducing flexibility in assessment practices (Kumar \& Wideman, 2014; Lombardi, Murray, \& Gerdes, 2011), perhaps by providing the option of a range of alternative assessments scaffolded by early formative work and timely feedback (Butcher, Sedgwick, Lazard, \& Hey, 2010). This emphasis on flexibility and on students working with faculty to shape their distinctive assessment paths also underscores the important role of students as partners in inclusive learning communities. 
A sustained theme that emerged in both the current review and Hockings' work is the extent to which stakeholders, particularly faculty, worry that inclusive assessment practices may reduce academic standards and erode educational quality (Ashworth, Bloxham, \& Pearce, 2010; Marquis et al., 2012; Marquis et al., 2016b). As Ashworth, Bloxham, and Pearce (2010) note, even faculty who value inclusion struggle to reconcile their desire to teach inclusively with their existing standards and practices. In contrast, Madriaga et al. (2010) frame inclusive teaching and assessment explicitly as a marker of quality, extending the notion articulated by advocates of universal design that inclusive assessment practices are effective for all students. This developing tension between competing discursive formations of inclusion raises the hopeful possibility that longstanding concerns about accessibility and academic standards might be beginning to shift.

\section{Institutional commitment and management}

The broader institutional contexts in which education unfolds represent a critical issue for inclusion. The interplay of and potential disconnects between administrative mandates, campus cultures, and the specifics of classroom implementation can have a strong impact on outcomes. Hockings (2010) pointed out that institutional-level commitment to inclusion is vital, yet research that considers institutional strategies remains piecemeal. Our review of the literature reinforced the position that advances in inclusive teaching and learning are primarily evident at the so-called coalface, involving faculty, students, and (to a lesser extent) educational developers in local teams rather than institutional strategies or programmatic initiatives. This comparative lack of attention to institution-wide or programmatic initiatives in the literature represents an important, persistent void. Indeed, it further underlines the need for a model, like that presented in Figure 1, which emphasises the significance of collaborations amongst diverse groups of actors across local, departmental, and institutional contexts working together towards inclusion.

Nevertheless, like Hockings (2010), we did identify some work beginning this process of considering institutional approaches to enhancing educational inclusivity (e.g., Devlin, Kift, Nelson, Smith, \& McKay, 2012). Forsyth and Cairnduff (2015), for example, argue that work needs to be done to understand better the disconnect between diverse populations and their institutions, and to develop adequate analytical tools with which to assess and understand these disconnections. Other studies emphasize that all institutional actors are responsible for inclusion, pointing toward the need to develop a systemic culture of inclusivity (Moriña Díez, López Gavira, \& Molina, 2015; Hughes, Corcoran, \& Slee, 2015). Similarly, Marquis et al. $(2012 ; 2016 b)$ present evidence that resonates with the idea that movement towards positive change will require both 'top down' and 'bottom up' pressures, attention to departmental contexts, and a strong evidence base. Echoing points made by Hockings (2010), authors also emphasize the need for adequate and coordinated central services and supports (Hughes, Corcoran, \& Slee, 2015; Marquis et al., 2012; 2016b). Bastiaens (2009), for example, advocates for institution-wide initiatives such as a diversity barometer to measure what is going on within institutions, integrated with resources, communities of practice involving different stakeholders (academic developers, professional staff, faculty), and shared knowledge. Each of these points speaks to the ways in which the actions of individual educators and students should be explored and understood in relation to a broader range of factors.

Questions of policy and legislation likewise figure interestingly within this larger context. While Hockings describes the importance of institution-wide policies and procedures that are integrated with other relevant policy documents, Hughes, Corcoran, and Slee (2015) argue that the fixity that is often enacted through policy needs to be replaced by flexibility. On a related note, Marquis et al. (2016b) 
question the efficacy of legislative change alone, while Pitman (2005) argues for the need to develop policy that simultaneously takes into consideration considerations of status. As noted above, framing inclusion in terms of quality, rather than compliance, may be a productive step towards shifting perceptions and institutionalizing inclusion (Madriaga et al., 2010).

One area that has received increasing attention since Hockings' review is the question of professional development opportunities connected to accessibility and inclusion (Considine et al., 2014; Heesink, de Koning, \& Visser, 2015; Thomas \& Heath, 2014). Recent scholarship suggests that development opportunities should be part of a systematic program of support (Moriña Díez, López Gavira, \& Molina, 2015) and have measures in place to identify and avoid outcomes such as changes in attitude but not in practice (Lombardi, Murray, \& Gerdes, 2011). Aligning with the 'whole-ofinstitution' approach described here, Marquis et al. (2016a) suggest the value of developing professional development programs that engage students, and combine attention to disciplinary and departmental contexts with interdisciplinary dialogue and knowledge sharing. Again, then, the potential of initiatives that operate both within and across institutional contexts and engage multiple stakeholders comes to the fore.

\section{CONCLUSION}

While sector-wide educational inclusion might be impossible to achieve fully, positive steps toward this goal can be taken through collaboration between students, academic developers, faculty, and senior administrators working as partners with awareness of the importance of thinking about inclusion at multiple levels. Hockings' (2010) framework explored existing work by major university stakeholders by analysing four basic university functions of inclusive curriculum design, inclusive curriculum delivery, inclusive assessment, and institutional commitment and management. The present review corroborates many of her findings, pointing out that similar issues continue to apply, offering further evidence to support her claims, and extending her work by offering new insights and complexities.

At the same time, the present review also points towards some compelling gaps that continue to require further attention and research. Foremost amongst these are the following underexplored arenas:

- Holistic institutional approaches that focus on partnerships between multiple stakeholders and attempt to foster cultural change within colleges and universities,

- Examples of excellent practice in the context of the department or degree program,

- Examples of the connections between policy and practice and related affordances and limitations, and

- Greater attention to international perspectives on inclusive teaching and learning. Each of these ideas is discussed, in turn, below.

In line with Hockings' recommendations from 2010, additional scholarship focusing on institution-level initiatives is still merited, as work focused in this way remained relatively sparse in the materials reviewed for this research. While several authors have offered perspectives on multiple meanings and dimensions of inclusive learning and teaching, examples of whole of institution approaches remain rare. This comparative gap is perhaps especially noteworthy for SoTL scholars to consider further. While localized, 'hands-on' work that considers questions of inclusive design, delivery, and/or assessment continues to be valuable, we urge SoTL scholars to consider further the ways in which such initiatives might interface with larger programmatic, disciplinary, and/or institutional efforts and initiatives. Work considering academic development initiatives focused on inclusion has begun to take meaningful steps in this direction. 
Another especially productive avenue for this type of broader research might be for scholars of teaching and learning to pay greater attention to inclusivity at the level of the degree program. With some exceptions (e.g., Testa \& Egan, 2014; Rasi, Hautakangas, \& Väyrynen, 2015), meanings and practices of inclusivity at a program level are generally ignored and are in need of much development. At the same time, such attention would align with calls for scholarly investigations at the programmatic level in the Scholarship of Teaching and Learning more broadly (Hubball, Pearson, \& Clarke, 2013; Matthews, Divan, John-Thomas, Lopes, Ludwig, Martini, Motley, \& Tomljenovic-Berube, 2013). This finding, which was not emphasized by Hockings in 2010, is a central outcome of our review.

Even more nascent in development is the notion of the relationships among and interconnectedness of inclusive learning and teaching practices with the governance and policies of the university and the leadership of its institutional managers. In effect, there is frequently a disconnect or, at the very least, a lack of systematic integration between the domains of teaching and management. This is clearly an area for further thinking, research, and modelling.

The final area requiring consideration is largely untapped: consolidating research and practices of inclusive learning and teaching from English-speaking universities with those of non-English speaking institutions conducting their own research and implementing their own versions of inclusive teaching practice. Inclusive education can be defined as a global movement in overcoming barriers to participation and success, but it has different scope depending on the international context. The definition of inclusion and its uses and effectiveness can vary widely depending on nations' differing states of prosperity and development, for instance (Armstrong, Armstrong, \& Spandagou, 2011). Gorski (2008) likewise addresses larger socio-political contexts to argue that education cannot be equal (and thus inclusive) while structural power imbalances are not addressed in curricula. Therefore, he argues, we cannot be inclusive while in effect maintaining the same educational hegemony that favours the social/political/educational status quo. Such considerations, which extend well beyond the level of the institution taken up in Hockings' model, are in need of much further research. We have attempted to model in this article the possibilities not only for international collaboration in authorship, but also for consolidating and synthesising international perspectives through a selection of literature drawn from a small number of languages. We look forward to further work in this area moving forward.

Educational inclusion is of fundamental significance to the social and political potential of higher education institutions. By following up on some of the recommendations offered in this preliminary review of the literature, scholars of teaching and learning can contribute to meeting this imperative.

Gwen Lawrie is an Associate Professor at the University of Queensland (AUS). Her teaching experiences and chemistry education research are grounded in enhancing the first-year experience for large classes.

Elizabeth Marquis is an Assistant Professor in the Arts \& Science Program at McMaster University (CAN) and Associate Director (Research) at McMaster's Paul R. MacPherson Institute for Leadership, Innovation, \& Excellence in Teaching.

Eddie Fuller is Professor at West Virginia University (US) and also Chair of the Department of Mathematics. He is currently completing an AAAS Science and Technology Policy Fellowship within the US Department of Homeland Security as a Big Data and Analytics Fellow.

Tara Newman is an Academic Developer at the University of Southern Queensland (AUS). She has extensive experience in building institutional and individual capacity in learning, teaching and scholarship. 
Mei Qiu is a recent graduate from the University of Queensland (AUS). She has completed a dual BSC/BEd program and recently qualified as a high school teacher, she has a deep interest in education research.

Milton Nomikoudis is a Senior Advisor, Office of the Dean of Learning and Teaching at RMIT University (AUS). He has extensive experience in developing practices that support diversity and inclusion.

Frits Roelofs is faculty member at HAN University of Applied Sciences (Netherlands). He has over 40 years' experience teaching Dutch language and literature and more recently has worked in evidencing the practices of Students as Partners.

Lianne van Dam is a recent graduate from HAN University of Applied Sciences (Netherlands). She also has a strong interest in developing Students as Partners and in 2016 has co-authored a book with Frits.

\section{REFERENCES}

Ainscow, M., Booth T., \& Dyson, A. (2006) Inclusion and the standards agenda: Negotiating policy pressures in England. International Journal of Inclusive Education, 10(4-5), 295-308.

Armstrong, D., Armstrong, A. C., \& Spandagou, I. (2011). Inclusion: By choice or by chance? International Journal of Inclusive Education, 15(1), 29-39.

Ashworth, M., Bloxham, S., \& Pearce, L. (2010). Examining the tension between academic standards and inclusion for disabled students: The impact of marking of individual academics' frameworks for assessment. Studies in Higher Education, 35(2), 209-223.

Avermaet, P., \& Sierens, S. (2012). Van periferie naar de kern. Omgaan met diversiteit in het onderwijs. Cultuuroverdracht en onderwijs in een multiculturele context. Academia Press: Gent.

Bastiaens, J. (2009). Een draagvlak voor diversiteit: drie instrumenten voor het hoger onderwijs. Onderwijsdag 2009 Arteveldehogeschool.

Bradley, J., \& Miller, A. (2010). Widening participation in higher education: Constructions of 'going to university.' Educational Psychology in Practice, 26(4), 401-413.

Brookfield, S. (2007). Diversifying curriculum as the practice of repressive tolerance. Teaching in Higher Education, 12(5), 557-568.

Burgstahler, S. E., \& Cory, R. C. (eds.) (2009). Universal design in higher education: From principles to practice. Cambridge: Higher Education Press.

Butcher, J., Sedgwick, P., Lazard, L., \& Hey, J. (2010). How might inclusive approaches to assessment enhance student learning in HE? Enhancing the Learner Experience in Higher Education, 2(1), 25-40.

Cole, D., \& Ahmadi, S. (2010). Reconsidering campus diversity: An examination of Muslim students' experiences. The Journal of Higher Education, 81(2), 121-139.

Considine, J. R., Mihalick, J. E., Mogi-Hein, Y. R., Penick-Parks, M. W., \& Van Auken, P. M. (2014). 'Who am I to bring diversity into the classroom?' Learning communities wrestle with creating inclusive college classrooms. Journal of the Scholarship of Teaching and Learning, 14(4), 18-30.

Cunningham, S. (2013). Teaching a diverse student body-A proposed tool for lecturers to self-evaluate their approach to inclusive teaching. Practice and Evidence of Scholarship of Teaching and Learning in Higher Education, 8(1), 3-27.

Dallas, B. K., Upton, T. D., \& Sprong, M. E. (2014). Post-secondary faculty attitudes toward inclusive teaching strategies. Journal of Rehabilitation, 80(2), 12-20.

Devlin, M., Kift, S. Nelson, K., Smith, L., \& McKay, J. (2012). Effective teaching and support of students from low socioeconomic status backgrounds: Practical advice for institutional policy makers and leaders. Sydney: Office of Learning and Teaching.

Dierker, L., Alexander, J., Cooper, J. L., Selya, A., Rose, J., \& Dasgupta, N. (2016). Engaging diverse students in statistical inquiry: A comparison of learning experiences and outcomes of under-represented and nonunderrepresented students enrolled in a multidisciplinary project-based statistics course. International Journal for the Scholarship of Teaching and Learning, 10(1).

Forsyth, H., \& Cairnduff, A. (2015). A scholarship of social inclusion in higher education: Why we need it and what it should look like. Higher Education Research \& Development, 34(1), 219-222. 
Fuller, M., Bradley, A., \& Healey, M. (2004). Incorporating disabled students within an inclusive higher education environment. Disability \& Society, 19(5), 455-468.

Gibson, S. (2015). When rights are not enough: What is? Moving towards new pedagogy for inclusive education within UK universities. International Journal of Inclusive Education, 19(8), 875-886.

Glowacki-Dudka, M., Murray, J., \& Concepción, D. W. (2012). Reflections on a teaching commons regarding diversity and inclusive pedagogy. International Journal for the Scholarship of Teaching and Learning, 6(2).

Gorski, P. (2008). Good intentions are not enough: A decolonizing intercultural education. Intercultural Education, 19(6), 515-525.

Grace, S. \& Gravestock, P. (2009). Inclusion and diversity: Meeting the needs of all students. New York: Routledge.

Groeneweg, B. (2015). Is inclusief onderwijs ook resultaatgericht? Meesterschap, 4(1), 31-35.

Heesink, E., de Koning, J. B., \& Visser, M. W. (2015). Een kwalitatief onderzoek naar de opvattingen van docenten over Passend Onderwijs met betrekking tot randvoorwaarden, attitudes en competenties.

Hockings, C. (2010). Inclusive learning and teaching in higher education: A synthesis of research. York: Higher Education Academy.

Hockings, C., Brett, P., \& Terentjevs, M. (2012). Making a difference-Inclusive learning and teaching in higher education through open educational resources. Distance Education, 33(2), 237-252.

Hubball, H., Pearson, M. L., \& Clarke, A. (2013). SoTL inquiry into broader curricular and institutional contexts: Theoretical underpinnings and emerging trends. Teaching \& Learning Inquiry, 1(1), 41-57.

Hughes, K., Corcoran, T., \& Slee, R. (2015). Health-inclusive higher education: Listening to students with disabilities or chronic illnesses. Higher Education Research \& Development. DOI: 10.1080/07294360.2015.1107885.

Kimmel, K., \& Volet, V. (2012). University students' perceptions of and attitudes towards culturally diverse group work: Does context matter? Journal of Studies in International Education, 16(2), 157-181.

Kumar, K. L., \& Wideman, M. (2014). Accessible by design: Applying UDL principles in a first year undergraduate course. Canadian Journal of Higher Education, 44(1), 125-147.

Ladson-Billings, G. (2014). Culturally relevant pedagogy 2.0: a.k.a. the remix. Harvard Educational Review, 84(1), 74-84.

Lee, A., Williams, R. D., Shaw, M. A., \& Jie, Y. (2014). First-year students' perspectives on intercultural learning. Teaching in Higher Education, 19(5), 543-554.

Lombardi, A. R., Murray, C., \& Gerdes, H. (2011). College faculty and inclusive instruction: Self-reported attitudes and actions pertaining to universal design. Journal of Diversity in Higher Education, 4(4), $250-261$.

Longstreet, C. S. (2011). The trouble with disciplining disciplines. New Directions for Teaching and Learning 125 , 21-29.

MacKinnon, D., \& Manathunga, C. (2003). Going global with assessment: What to do when the dominant culture's literacy drives assessment. Higher Education Research \& Development, 22(2), 131-144.

Madriaga, M., Hanson, K., Heaton, C., Kay, H., Newitt, S., \& Walker, A. (2010). Confronting similar challenges? Disabled and non-disabled students' learning and assessment experiences. Studies in Higher Education, 35(6), 647-658.

Marquis, E., Jung, B., Fudge-Schormans, A., Vajoczki, S., Wilton, R., Baptiste, S., \& Joshi, A. (2012). Creating, resisting or neglecting change: Exploring the complexities of accessible education for students with disabilities. The Canadian Journal for the Scholarship of Teaching \& Learning 3(2).

Marquis, E., Jung, B., Fudge Schormans, A., Lukmanji, S., Wilton, R., \& Baptiste, S. (2016a). Developing inclusive educators: Enhancing the accessibility of teaching and learning in higher education. International Journal for Academic Development.

Marquis, E., Fudge Schormans, A., Jung, B., Vietinghoff, C., Wilton, R., \& Baptiste, S. (2016b). Charting the landscape of accessible education for post-secondary students with disabilities. Canadian Journal of Disability Studies, 5(2), 31-71.

Matthews, K., Divan, A., John-Thomas, N., Lopes, V., Ludwig, L., Martini, T., Motley, P., \& Tomljenovic-Berube, A. M. (2013). SoTL and students' experiences of their degree-level programs: An empirical investigation. Teaching \& Learning Inquiry, 1(2), 75-89.

May, H., \& Bridger, K. (2010). Developing and embedding inclusive policy and practice in higher education. York: Higher Education Academy.

McArthur, J. (2010). Achieving social justice within and through higher education: The challenge for critical pedagogy. Teaching in Higher Education, 15(5), 493-504.

20 Lawrie, G., Marquis, E., Fuller, E., Newman, T., Qui, M., Nomikoudis, M., Roelofs, F., \& van Dam, L. (2017). Moving towards inclusive learning and teaching: A synthesis of recent literature. Teaching \& Learning Inquiry, 5(1). http://dx.doi.org/10.20343/teachlearninqu.5.1.3 
Moriña Díez, A., López Gavira, R., \& Molina, V. M. (2015). Students with disabilities in higher education: A biographical-narrative approach to the role of lecturers. Higher Education Research \& Development, 34(1), 147-159.

Moriña, A., Cortés-Vega, M. D., \& Molina, V. M. (2015). Faculty training: An unavoidable requirement for approaching more inclusive university classrooms. Teaching in Higher Education, 20(8), 795-806.

Ouellett, M. (ed.) (2005). Teaching inclusively: Resources for course, department and institutional change in higher education. Stillwater: New Forum's Press.

Pitman, T. (2005). Unlocking the gates to the peasants: Are policies of 'fairness' or 'inclusion' more important for equity in higher education? Cambridge Journal of Education, 45(2), 281-293.

Rasi, P., Hautakangas, M., \& Väyrynen, S. (2015). Designing culturally inclusive affordance networks into the curriculum. Teaching in Higher Education, 20(2), 131-142

Riddell, S., Weedon, E., Fuller, M., Healey, M., Hurst, A., Kelly, K., \& Piggott, L. (2007). Managerialism and equalities: Tensions within widening access policy and practice for disabled students in UK universities. Higher Education, 54(4), 615-628.

Shuman, H. (2007). Passend onderwijs_-Pas op de plaats of stap vooruit? Tijdschrift voor Orthopedagogiek, 46, 267-280.

Smith, F. G. (2012). Analysing a college course that adheres to the universal design for learning (UDL) framework. Journal of the Scholarship of Teaching and Learning, 12(3), 31-61.

Tervalon, M., \& Murray-Garcia, J. (1998). Cultural humility versus cultural competence: A critical distinction in defining physician training outcomes in multicultural education. Journal of Health Care for the Poor and Underserved, 9, 117-25.

Testa, D., \& Egan, R. (2014). Finding voice: The higher education experiences of students from diverse backgrounds. Teaching in Higher Education, 19(3), 229-241.

Thomas, L., \& Heath, J. (2014). Institutional wide implementation of key advice for socially inclusive teaching in higher education. A practice report. The International Journal of the First Year in Higher Education, 5(1), 125-133.

Thomas, L., \& May, H. (2010). Inclusive learning and teaching in higher education. York: Higher Education Academy.

Trigwell, K. (2013). Evidence of the impact of scholarship of teaching and learning purposes. Teaching \& Learning Inquiry, 1(1): 95-105.

Van Gastel, T. C. M., Erkaslan, E., \& De Jongste, S. C. (2014). In hoeverre zijn leerkrachten voorbereid in het onderwijzen van functioneel diverse kinderen in het regulier basisonderwijs?

Copyright for the content of articles published in Teaching \& Learning Inquiry resides with the authors, and copyright for the publication layout resides with the journal. These copyright holders have agreed that this article should be available on open access under a Creative Commons Attribution License 4.0 International (https://creativecommons.org/licenses/by/4.0). The only constraint on reproduction and distribution, and the only role for copyright in this domain, should be to give authors control over the integrity of their work and the right to be properly acknowledged and cited, and to cite Teaching \& Learning Inquiry as the original place of publication. Readers are free to share these materials - as long as appropriate credit is given, a link to the license is provided, and any changes are indicated. 